NOTAS

\title{
NOTA SOBRE SCHILLER (LA HERENCIA LIBERAL Y ROMÁNTICA)
} Ignacio Díaz de la Serna*

$\mathbf{E}_{1}$ temporáneamente a la Restauración con el nombre de liberalismo no sólo fue una doctrina de la libertad política. Llegó a implicar además una voluntad casi generalizada de adherirse a las instituciones y valores que habían surgido con la Revolución francesa, así como la urgencia de manifestar una férrea oposición a la simple posibilidad de que se retrocediera a la antigua sociedad con la monarquía restaurada. La igualdad civil que reducía a la nobleza a la condición común y la exclusión de cualquier derecho de inspección clerical sobre el gobierno, fueron para la tendencia liberal conquistas tan importantes como el conjunto de libertades civiles garantizados por la Declaración de los Derechos del Hombre. Comprendido esto, no sería temerario concluir que el repudio hacia el Antiguo Régimen conllevó en todo momento una profesión de fe liberal. En otras palabras, la libertad no podía ausentarse de la sociedad mo-

* Departamento Académico de Estudios Generales, ITAM. derna sino por accidente y sólo temporalmente. Por encima del rechazo de un pasado humillante, el anhelo de libertad constituyó un pregón.de fe en el porvenir.

Dicho anhelo fue expresado también por la mayoría de las voces que formaron parte del romanticismo. Los escritores románticos, tanto alemanes como franceses, hablaron de «perfectibilidad», refiriéndose con ello al proyecto de dar a luz en esa época a un Hombre libre. De esta manera, el amplio crédito que acabó disfrutando el liberalismo se debió al hecho de que reunía en su seno, junto con la libertad, los elementos de la causa moderna: igualdad y progreso. La libertad, empero, fue sin duda el alma inspiradora de esa doctrina.

Antes de proseguir, resulta importante aclarar un punto. Actualmente en ocasiones se confunde la doctrina liberal con su variante económica. $\mathrm{Mu}$ chas veces se entiende por liberalismo la doctrina de los economistas liberales que desarrollaron Bentham, Mill, y otros. En ella se considera que la empresa y el libre mercado constituyen 
dos condiciones primordiales que favorecen el bienestar público. Es cierto que hacia 1789 la libertad también se comprendía en términos económicos. Pero lo que surgió en ese entonces fue esencialmente una doctrina de los derechos del hombre como individuo, siendo la propiedad y su libre disposición sólo uno de esos derechos, el menos absoluto de ellos, ya que fue el único que se estimó discutible. Si bien puede argumentarse en favor o en contra de la libertad económica, hay que conceder que en este aspecto el liberalismo, desde sus orígenes, consideró el interés público como medida para llevar a cabo una reglamentación de las actividades económicas. No obstante, se olvida a menudo cuál fue, en toda su amplitud, la herencia liberal, la cual no abarca exclusivamente modelos precisos de producción e intercambio, sino un estatuto general de los derechos que corresponden a todo individuo civilizado.

De hecho, la economía de mercado ha coexistido con los reglamentos que apoyan el interés público. Esto sucedió en los comienzos de la era industrial. La libertad económica no fue en el siglo XIX más que una fórmula digamos algebraica que las instituciones nunca encarnaron. Con la experiencia de nuestro siglo, muchos han querido comprobar que una de las condiciones de la sobrevivencia de las libertades civiles reside en una proporción suficientemente grande de libertad en la economía. Pero el siglo XIX mostró ya desde hace tiempo que la existencia de la libre empresa no basta por sí misma para asegurar el respeto de los derechos del hombre. En consecuencia, cuando se habla de liberalismo, es preciso tener en cuenta esa herencia espiritual en toda su extensión, como una filosofía que trata de las relaciones del individuo con el Estado, sin olvidar que la libertad política supone una doctrina de libertad moral. Schiller no difiere en este sentido al afirmar: «Cuando la Naturaleza aspire a afirmar su multiplicidad en el edificio moral de la sociedad, no rompa en manera alguna la unidad moral. La forma victoriosa se halla tan lejos de la uniformidad como del desorden. Totalidad de carácter ha de tener el pueblo digno y capaz de trocar el Estado de necesidad por el Estado de libertad. ${ }^{1}$

El liberalismo y el romanticismo, en cuanto que profesan la perfectibilidad humana, asientan como aspiración ciertos valores que deben realizarse humanamente, y cuya verosimilitud, sin embargo, no se podría fundar en la humanidad misma a la cual se le proponen como fin. Ambos tuvieron que recurrir, pues, al antiguo fundamento trascendente del Bien, aunque de forma distinta a como se había postulado desde la herencia platónica. La libertad, en efecto, mantiene una relación estrecha con el ideal. El impulso que en nosotros la afirma y dignifica es el mismo que nos transporta a una región de existencia superior en la que cesa para siempre la esclavitud frente al instinto.

${ }^{1}$ Schiller Friedrich von, La educación estética del hombre, 1968, 4a , Madrid, Espasa Calpe, Col. Austral, trad. Manuel García Morente, p. 23. 
NOTAS

Así, los dos son arrastrados por una lógica de la trascendencia, tratando de definirla al margen de la dogmática cristiana. Al referirse a la trascendencia, hablan sobre la experiencia inmediata según la cual el valor o la libertad implican una distancia respecto de la naturaleza. El recurso religioso puede subsistir, pero ya no está en el centro de sus preocupaciones respectivas. Se debaten nuevos asuntos para los cuales ese recurso, en opinión de quienes lo invocan, no es una respuesta necesaria. $\mathrm{Si}$ acaso ambos traslucen por momentos un cierto tinte de espiritualismo, es simplemente porque aceptan que las religiones antiguas y el cristianismo contribuyeron como ningún otro elemento a la educación del género humano.

«La gran dificultad advierte Schiller consiste, pues, en que la sociedad física no debe cesar un solo momento de existir en el tiempo, mientras que la sociedad moral se forma en la idea; no es lícito poner en peligro la existencia del hombre por respeto a la dignidad del hombre. Cuando el relojero tiene que componer un reloj, detiene el movimiento de las ruedas. Mas el reloj viviente del Estado no puede suspender su marcha; hay que componerlo sin pararlo, y cambiar la rueda sin interrumpir el movimiento de rotación. Precisa, pues, buscar un sólido apoyo que mantenga la continuidad social y la haga independiente del Estado natural que se trata de deshacer». ${ }^{2}$

La dignidad humana es la verdad central de una fe que comparten am-

${ }^{2} I b i d$, p. 18. bos movimientos, pues experimentaron por igual la necesidad del hombre de definirse plenamente y no tanto esa otra necesidad de encontrar una evidencia sobre la plenitud divina. ${ }^{3}$ Lo que está en juego es la superación virtualmente metafísica de la naturaleza, la cual tiene la finalidad de autorizar una exigencia humana. $\mathrm{O}$ mejor, esa exigencia es la humanidad misma. Por consiguiente, el cálculo ideal de la felicidad futura mediante el sacrificio de la situación presente corresponde por entero a lo humano y su actividad fundamentadora del progreso.

Ante la naturaleza y la noción de necesidad natural, tanto la actitud del romanticismo como la del liberalismo están constituidas de modo semejante. Existe una curiosa mezcla de adhesión y de reserva. Por encima de esta ambigüedad, tienden a salvaguardar la autonomía del hombre. Sin embargo, si el progreso no es otra cosa que el desenvolvimiento de nuestra naturaleza, se corre el peligro de concebirlo como fatal e inexorable. ¿Cómo garantizar entonces que es efectivamente progreso y no desarrollo ciego; que en él se realiza, a medida que se avanza, el proyecto del ideal? A la lógica de la trascendencia se une la convicción de que el tiempo obra en favor del hom-

${ }^{3}$ Schiller alude a la dignidad en la Carta XXIV, donde dice: «Es propio del hombre juntar en su condición lo más alto y lo más bajo; y si su dignidad estriba en distinguir estrictamente lo uno de lo otro, en cambio su felicidad consiste en suprimir hábilmente esa diferencia», Ibid, p.110. 
bre. La gran metamorfosis del mundo que trajo consigo la Revolución francesa representa la prueba triunfal de que el transcurso de la historia posee una dirección: la evolución objetiva que permite identificar lo moral con el progreso, legitimando así el presente como aliado en la causa de la libertad. Tal es lo que expresan las palabras de Melchthal cuando se conduele de su padre, quien ha quedado privado de la vista por orden del tirano que gobierna los cantones de Schwyz, Uri y Unterwald: «No verás, padre, el día de la libertad, pero si oirás sus cánticos. Cuando de Alpe en Alpe se levanten las llamas de las hogueras y se derrumben las fortalezas de la tiranía, Suiza entera irá a tu casa a darte la feliz nueva...» 4

Cuando se considera de manera general la marcha histórica de la humanidad, se constata que en ese movimiento progresivo todo ha sido imprescindible y útil. Los abusos de ayer justifican las mejoras de hoy. Dichos abusos tuvieron su tiempo útil, pero su utilidad está lejos de implicar que deban ser restituidos cuando desaparecen. Mientras sirven de algo se mantienen por sí mismos, y cuando caen, es porque su conveniencia ha terminado. No es extraño entonces que románticos y liberales hayan visto la Revolución con buenos ojos por ser un suceso que se había propuesto introducir la justicia en la sociedad, es decir, el imperio de la ley

${ }^{4}$ Guillermo Tell en Obras selectas, 1969 , Madrid, Bruguera, Col. Libro Clásico, trad. José Miguel Minguez Sender, p. 57-8. moral en las relaciones mutuas de los ciudadanos y en las del gobierno con los ciudadanos. El progreso moral y material de la civilización es irresistible, y bien puede reputársele como el destino del género humano.

Aquí se perfila un dilema entre el punto de vista ideal y el de la necesidad histórica, ya que se vislumbra una distancia entre el ideal filosófico y las circunstancias concretas. No obstante, el progreso tiene por objetivo reducir esa distancia. La pregunta que no puede evitarse es si los acontecimientos y la vida del mundo social están subordinados, como el mundo físico, a la influencia de causas externas y necesarias, o bien el hombre, mediante su pensamiento y su voluntad, se halla en condición de dirigirlos y gobernarlos.

En Schiller se plantea este dilema en los siguientes términos: «Ni abstracción ni experiencia pueden conducirnos a la fuente de donde emanan los conceptos de universalidad y necesidad... Fero basta que la conciencia del propio yo se presente; que, con la inalterable unidad de la misma, quede instaurada la ley de la unidad en cuanto para el hombre es, y en todo lo que por el hombre debe ser; en suma, en el conocimiento y en la acción»"

Aunado al tema de la libertad, surge en el interior de ambos movimientos el conflicto entre las nociones de derecho y de utilidad. La inquietud por intentar diferenciarlas estuvo en el

${ }^{5}$ La educación estética del hombre, op. cit., p.89. 
NOTAS

corazón del liberalismo y también preocupó sobremanera a la mayoría de los románticos. Por una parte, los liberales, empecinados en buscar una doctrina política positiva, exenta de postulados teológicos, se sintieron tentados por el utilitarismo de Bentham. Sin embargo, una adhesión incondicional del liberalismo a esa doctrina no dejaba de ofrecer serias dificultades. Por su parte, el romanticismo la combatió abiertamente porque repudiaba la moral del interés. Varios liberales, sobre todo franceses como Benjamin Constant y Guizot, elaboraron una crítica del utilitarismo que no habría de diferir mucho de la que los románticos emprendieron. El punto común que habríade reunirlos fue dilucidar si estaba permitido, en un momento dado, resistir a una ley en vigor invocando un derecho ideal aun en contra de la conveniencia social inmediata. El utilitarismo había iniciado la discusión al negar la validez de todo derecho ajeno a las prescripciones de la ley positiva. En fin de cuentas, liberales y románticos consideraban que el principio de utilidad despertaba en el espíritu de los hombres la esperanza de un beneficio y no el sentimiento de un deber. Más aún, creyeron que la evaluación de un beneficio es completamente arbitraria en la medida en que es la imaginación quien decide. En todo caso, ni sus errores ni caprichos pueden alterar la noción de deber. Una acción puede ser más o menos justa, pero nunca más o menos útil. $\mathrm{Si}$ un individuo perjudica a sus semejantes, viola los derechos que les corresponden. Esta es una verdad indiscutible. Quien juzgue esa violación simplemente por su utilidad, es probable que se equivoque $y$ encuentre utilidad en ella. Por consiguiente, el principio de utilidad es mucho más indefinido que el de derecho. De aquí que sea imperioso separar la idea del derecho y la noción de utilidad. La herencia kantiana conseguía, pues, extenderse en el siglo XIX.

«iCabe censurar al Estado por haber perdido de vista la dignidad de la naturaleza humana, cuando se trataba de defender su existencia?», se pregunta Schiller en la Carta $V$ de La educación estética del hombre. La idea de libertad en el transcurso de la Revolución había sido comprometida por los años del Terror. Además, románticos y liberales veían con desconfianza que una doctrina sobre la libertad nacida del Contrato social de Rousseau colocara la soberanía del individuo un peldaño por debajo de una voluntad general omnipotente, acabando por apoyar a una dictadura. La libertad encumbrada en esas alturas había engendrado lo contrario de lo que se había propuesto. Era preciso meditar entonces cómo la libertad podía ser algo más que un concepto vacío, una nueva tiranía.

Se creyó que la inclinación dictatorial de la política revolucionaria había tenido su origen en un error. El modelo de libertad desarrollado en las ciudades de la antigüedad grecolatina es el que la Revolución había retomado como modelo posible. La República total concebida por Rousseau y Robespierre ignoró una doctrina moderna de la libertad, exenta ya de la coacción 
que había caracterizado al civismo grecorromano. En efecto, dentro de la civilización moderna ya no era factible pensar siquiera en una participación cotidiana de cada ciudadano en el poder. Por el contrario, urgía diseñar una nueva sociedad donde se garantizaran el goce de derechos civiles y una independencia individual. La libertad ejercida en la antigüedad exigía limitar esos derechos y esa independencia. Lo que el siglo XIX denominó «libertad civil» fue prácticamente desconocido para los pueblos antiguos porque en ellos los individuos quedaban sometidos a una jurisdicción social casi irrestricta. Los ciudadanos que forman los Estados modernos comparten el poder sólo por la vía indirecta de la representación. De esta manera, el siglo XIX deseará la libertad entendida como libertad individual; lo que Schiller llama «libertad interior», la cual sólo la muerte puede arrebatar al hombre.

La garantía de esa libertad es la libertad política. Esta última es, en consecuencia, indispensable. A la independencia se añade la necesidad de progresar. Ambas constituyen el camino del perfeccionamiento.

Precisar esa noción de libertad condujo después a una reflexión doctrinal sobre la naturaleza de la soberanía. Aunque la Revolución había trasladado la soberanía del monarca a la nación, se estimó que el verdadero problema residía menos en decidir a quién pertenecía que en definir su extensión y sus límites. Porque reconocer en abstracto la soberanía del pueblo no incrementa en absoluto la libertad de los individuos. Cuando se acepta que la soberanía del pueblo es y deber ser ilimitada, se crea en la sociedad un poder excesivamente grande, sin importar ya cuál es la mano que lo maneja. El dominio de la sociedad sobre el individuo no puede franquear legítimamente ciertas fronteras. Hay sin duda una parte de la existencia humana que se conserva a toda costa independiente y que está fuera de cualquier competencia social. La soberanía se manifiesta, pues, de modo limitado y relativo. En el punto donde comienza la independencia de la existencia individual, se detiene la jurisdicción de esa soberanía. Aun el consentimiento de la mayoría no basta para legitimar sus actos. Cuando una autoridad rebasa dichos limites, se llame individuo o nación, se hace tan culpable como el peor de los déspotas.

Así, la idea moderna de libertad se opuso a la idea de libertad expuesta en el Contrato social, ya que en él se estipulaba la alienación de los derechos del individuo en favor de la autoridad colectiva, a cambio de la participación de cada ciudadano en el voto de la ley. Allí se aseguraba, por lo menos, que la colectividad no podría legislar contra los intereses de sus miembros porque todos constituían una voluntad general. Para el siglo XIX, los resultados del proyecto rousseauneano parecieron catastróficos. Extender a todos los rincones privados la competencia de la ley equivalía a organizar metódicamente la tiranía. El mayor de los errores había consistido en divinizar al legislador, fuese éste uno o muchos. 
NOTAS

En conclusión, ganó importancia la idea de que debía existir un ámbito donde el poder no incursionara y que la ley no invadiera, so pena de una ilegitimidad radical. Este principio se irguió como un auténtico imperativo categórico: es el acto de conciencia mediante el cual cada individuo establece su derecho inalienable. Filosóficamente, manifiesta un orden ideal que trasciende la fuerza; históricamente, ayuda a definir el grado de civilización más avanzado al que el hombre ha llegado, y cuyo desconocimiento, a partir de ese momento, significaría regresar a la barbarie. Sólo así el principio de libertad adquiere vida y puede realizarse. En Schiller, por ejemplo, el ideal de libertad entraña el estado estético. Ley de ese estado es «dar libertad por medio de la libertad». 